\title{
Differential gene regulation by the SRC family of coactivators
}

\author{
Hua Zhang, ${ }^{1}$ Xia Yi, ${ }^{1}$ Xiaojing Sun, Na Yin, Bin Shi, Huijian Wu, Dan Wang, Ge Wu, \\ and Yongfeng Shang ${ }^{2}$ \\ Department of Biochemistry and Molecular Biology, Peking University Health Science Center, Beijing 100083, China
}

\begin{abstract}
SRCs (steroid receptor coactivators) are required for nuclear receptor-mediated transcription and are also implicated in the transcription initiation by other transcription factors, such as STATs and NFKB. Despite phenotypic manifestations in gene knockout mice for SRC-1, GRIP1, and AIB1 of the SRC (Steroid Receptor Coactivator) family indicating their differential roles in animal physiology, there is no clear evidence, at the molecular level, to support a functional specificity for these proteins. We demonstrated in this report that two species of SRC coactivators, either as AIB1:GRIP1 or as AIB1:SRC-1 are recruited, possibly through heterodimerization, on the promoter of genes that contain a classical hormone responsive element (HRE). In contrast, on non-HRE-containing gene promoters, on which steroid receptors bind indirectly, either GRIP1 or SRC-1 is recruited as a monomer, depending on the cellular abundance of the protein. Typically, non-HRE-containing genes are early genes activated by steroid receptors, whereas HRE-containing genes are activated later. Our results also showed that SRC proteins contribute to the temporal regulation of gene transcription. In addition, our experiments revealed a positive correlation between $A I B 1 / c-m y c$ overexpression in $\mathrm{ER}^{+}$breast carcinoma samples, suggesting a possible mechanism for AIB1 in breast cancer carcinogenesis.
\end{abstract}

[Keywords: Gene regulation; coactivators; steroid receptors]

Supplemental material is available at http://www.genesdev.org.

Received February 16, 2004; revised version accepted May 21, 2004.

Gene transcription activation by transcription factors such as nuclear receptors is accomplished through the recruitment of a series of coactivators. Coactivator proteins fulfill their functions through protein-protein interactions that bridge transcription factors and the basal transcription machinery and through their chromatin remodeling activities that facilitate the assembly of a transcription initiation complex (Glass and Rosenfeld 2000). Several general coactivators, such as $\mathrm{CBP} / \mathrm{p} 300$ and p300/CBP-associated protein factor (pCAF), are recruited by transcription factors to mediate their transcriptional activities (Glass and Rosenfeld 2000). These proteins are known to possess intrinsic histone acetyltransferase (HAT) activity and are capable of chromatin modification by histone acetylation. The general coactivators can also be recruited by interaction with more specific coactivators, including members of the SRC (Steroid Receptor Coactivator) family (also referred to as p160 family) SRC-1, TIF2/GRIP1/SRC-2 (hereafter referred to as GRIP1), and pCIP/ACTR/AIB1/RAC3/TRAM1/SRC-3 (hereafter referred to as AIB1; Glass and Rosenfeld 2000),

\footnotetext{
${ }^{1}$ These authors contributed equally to this work.

${ }^{2}$ Corresponding author.

E-MAIL jason@bjmu.edu.cn; FAX 86-10-82801355.

Article and publication are at http://www.genesdev.org/cgi/doi/10.1101/ gad.1194704
}

which were shown to enhance nuclear receptor-mediated gene transcription as well as gene transactivation by other transcription factors.

The physiological significance of the SRC family and the functional specificity of these proteins have been an area of extensive study. In this context, AIB1 has been found to be strongly amplified and/or overexpressed in $64 \%$ of primary breast cancers as well as in some primary ovarian tumors (Anzick et al. 1997; Bautista et al. 1998); and translocation between the GRIP1 gene and the MOZ (monocytic zinc finger) gene encoding a HAT protein (Champagne et al. 2001) has been identified in human acute myeloid leukemia (Carapeti et al. 1998), suggesting important functions of SRC proteins in physiology. Genetic studies with gene ablation showed that, whereas both male and female SRC1-null mice are viable and fertile, they exhibit partial resistance to several hormones, including estrogen, progestin, androgen, and thyroid hormones (Xu et al. 1998; Weiss et al. 1999); elimination of $A I B 1$ has revealed that it is required for normal mouse growth (Wang et al. 2000; Xu et al. 2000), as well as for some female reproductive functions $(\mathrm{Xu}$ et al. 2000); and, in contrast to SRC-1 and AIB1 knockout mice, there is impairment of fertility in both male and female GRIP1-null mice (Gehin et al. 2002). A recent study showed that GRIP-null mice are protected against obesity and display enhanced adaptive thermogenesis, 
whereas $S R C$-1-null mice are prone to obesity due to reduced energy expenditure (Picard et al. 2002).

Despite the variation in phenotypic manifestations of these $S R C$-null mice, which suggests differential biological activities of the SRC proteins, there is as yet no clear evidence, at the molecular level, to indicate functional specificities for the three members of the SRC family. Structurally, SRC-1, GRIP1, and AIB1 share $40 \%$ overall sequence identity, and they all contain, in the $\mathrm{N}$ terminus, a basic helix-loop-helix (bHLH) domain that is known as a dimerization and DNA interaction domain as well as a PAS domain, which is known to be involved in protein-protein interaction. Three LXXLL motifs, also known as NR boxes (for nuclear receptor binding), are centrally located in all three proteins (Heery et al. 1997; Darimont et al. 1998; McInerney et al. 1998). Although various biochemical approaches have implied that an individual member of the SRC family may possess functional specificities in a manner of propensity or selectivity for different types or isotypes of nuclear receptors or other transcription factors (Kraichely et al. 2000; Issa et al. 2001; Barkhem et al. 2002; Beischlag et al. 2002; Bommer et al. 2002), most in vitro studies and transfection experiments indicate that each member of the SRC family is capable of interaction with multiple nuclear receptors, and that a particular nuclear receptor is able to interact with all three members of the SRC family.

Nuclear receptors, especially steroid receptors such as ER and androgen receptor (AR), exhibit a bimodal pattern of gene regulation in the presence of their ligands. Some genes are activated quickly and others are only activated by prolonged stimulation with the ligands. In addition, tissue-specific activities have been well recognized for nuclear receptors, and these clearly are a reflection of their differential gene regulation in different tissues. However, how the precise regulation of gene expression is achieved, and, as important players in nuclear receptor signaling, how SRC proteins, as a whole family, contribute to the temporal regulation of transcription and to the tissue-specific functions of nuclear receptors, are not understood.

In this report, we investigated the functional specificity of all three members of the SRC family and provided the mechanistic and pathobiological insights into the temporal gene regulation by steroid receptors.

\section{Results}

Steroid receptors such as ER and AR regulate gene transcription either by binding directly to the promoter of target genes or by binding indirectly through an as yet not fully characterized mechanism involving other transcription factors such as AP1. Genes regulated through direct ER binding, such as cathepsin $D$ (Augereau et al. 1994) and EBAG9 (for ER-binding fragment-associated antigen 9; Watanabe et al. 1998; Tsuchiya et al. 2001) are activated slowly and typically harbor a hormone responsive element (HRE) with a consensus sequence of $5^{\prime}$ AGGTCAnnnTGACCT-3' in their promoters. In contrast, genes regulated by binding ER indirectly are quickly activated and include $c-M y c$ (Dubik and Shiu 1992) and IGF-I (Umayahara et al. 1994), whose promoters do not contain a classical HRE. Analogously, genes regulated through direct AR binding, such as PSA (prostate specific antigen), typically harbor HREs with a consensus sequence of 5'-GGTACAnnnTGTTCT-3' in their promoters (Cleutjens et al. 1996, 1997) and need a longer time to be activated; genes regulated by binding AR indirectly are early genes such as c-Myc (Bieche et al. 2001; Silva et al. 2001), which does not contain a classical HRE in its promoter. In previous studies, we and others have shown that SRC-1, GRIP1, and AIB1 are all implicated in both ER- and AR-mediated gene transcription (Shang et al. 2000, 2002; Louie et al. 2003).

To investigate whether there are any coactivation specificities for these three coactivators in ER- and ARmediated gene transcription, we first sought to investigate the pattern of SRC-1, GRIP1, and AIB1 recruitment on different gene promoters. The estrogen-dependent human mammary carcinoma cell line T-47D and the human endometrial carcinoma cell line ECC-1, and an androgen-responsive human prostate carcinoma cell line LnCAP, were used for this experiment. EBAG9 and c$M y c$ were chosen to represent HRE-containing target genes and non-HRE-containing target genes, respectively, in ER-mediated transcription, and PSA and $c-M y c$ were chosen to represent HRE-containing target genes and non-HRE-containing target genes, respectively, in AR-mediated transcription. The temporal difference in steroid-induced expression of these genes was confirmed first in our experimental system. In these experiments, T-47D cells and ECC-1 cells were grown in the absence of estrogen, and LnCAP cells were grown in the absence of androgen, for at least $3 \mathrm{~d}$, followed by no treatment or treatment with saturating levels of $17 \beta$-estradiol (E2) or dihydrotestosterone (DHT) for $6 \mathrm{~h}$, and the mRNA expression of $c-M y c, E B A G 9$, and PSA was analyzed at different times of treatments by real-time RT-PCR. These experiments indicated that $c-M y c$ activation occurred much earlier and peaked at $1 \mathrm{~h}$ of E2 or DHT treatment in these cells, whereas EBAG9 and PSA activation developed later and peaked at 4-6 h of E2 or DHT treatment (Supplementary Fig. 1). We then investigated the coactivator recruitment on the promoter of these genes. In these experiments, T-47D cells and ECC- 1 cells were grown in the absence of estrogen, and LnCAP cells were grown in the absence of androgen, for at least $3 \mathrm{~d}$, followed by no treatment or treatment with saturating levels of E2 or DHT for $45 \mathrm{~min}$. The presence of SRC family coactivators on the estrogen or androgen target gene promoters was first determined using chromatin immunoprecipitation (ChIP) with antibodies against one of the coactivators. Then, both the precipitates and the supernatants were subjected to reimmunoprecipitation (ChIP/ Re-IP) with antibodies against a second SRC protein. As shown in Figure 1A (top), the presence of all three members of the SRC family (SRC-1, GRIP1, and AIB1) could be detected on the promoter of the EBAG9 gene after treatment with E2. This could be explained by one of the following scenarios: each coactivator could be associated 
A
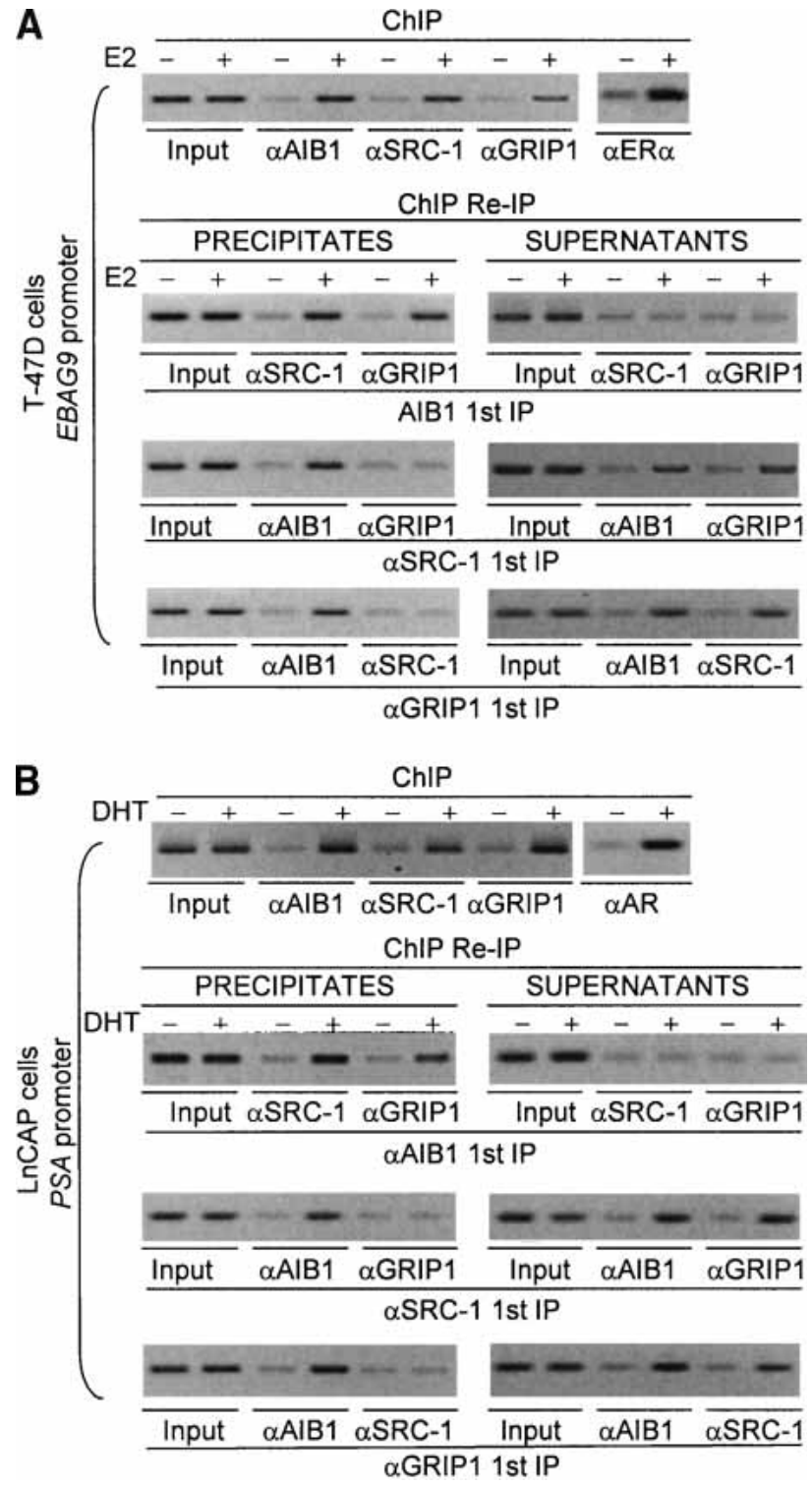

Figure 1. The pattern of recruitment of the members of the SRC family, SRC-1, GRIP1, and AIB1, on the promoters of the HRE-containing genes EBAG9 in T-47D cells $(A)$ and PSA in LnCAP cells $(B)$. Cells were grown in phenol red-free medium (DMEM for T-47D and RPMI-medium 1640 for LnCAP cells) supplemented with $10 \%$ charcoal-dextran-stripped FBS for at least $3 \mathrm{~d}$, and left untreated or treated with $100 \mathrm{nM}$ of E2 or 100 $\mathrm{nM}$ of DHT for $45 \mathrm{~min}$. ChIP assays and ChIP/Re-IP experiments were performed using specific antibodies against SRC-1, GRIP1, and AIB1.

with a different promoter in different cells; pairs of three coactivators could be associated with a different promoter in different cells; or the three coactivators could act as a triplet. As mentioned earlier, the SRC proteins contain bHLH and PAS domains, which are known for mediating protein-protein interactions. Thus, dimerization or trimerization of SRC proteins is also possible. Our ChIP/Re-IP experiments demonstrate that in precipitates, whereas the EBAG9 gene promoter immuno- precipitated with antibodies against AIB1 could be reimmunoprecipitated with antibodies against either SRC-1 or GRIP1, an initial ChIP with antibodies against either SRC-1 or GRIP1 only gave detection of the EBAG9 gene promoter when reimmunoprecipitated with antibodies against AIB1 (Fig. 1A, bottom three panels, left). On the other hand, supernatants from ChIP with antibodies against AIB1 showed no detection of the EBAG9 gene promoter when ChIP/Re-IP was done with antibodies against either SRC-1 or GRIP1. In contrast, supernatants from initial ChIPs with antibodies against either SRC-1 or GRIP1 still contained AIB1- and GRIP1-bound or AIB1- and SRC-1-bound EBAG9 gene promoters, respectively (Fig. 1A, bottom three panels, right). To rule out the potential cross-reaction among these antibodies, in vitro-translated SRC proteins or cell extracts containing endogenous SRCs were immunoprecipitated by SRC antibodies. Triplicate blots containing precipitated SRC proteins resolved by SDS-PAGE were probed with antibodies against SRC-1, GRIP1, or AIB1. Antibody specificities were clearly demonstrated by these studies (data not shown). These data strongly suggested that a pair between AIB1 and SRC-1 or between AIB1 and GRIP1 existed on the promoter of the EBAG9 gene. Similar results were obtained with the PSA gene promoter in LnCAP cells (Fig. 1B) as well as with the EBAG9 gene promoter in ECC-1 cells (data not shown). The association of AR or ER with SRC-1, GRIP1, or AIB1 was confirmed by coimmunoprecipitations (see Supplementary Fig. 2). Collectively, these data indicate that, on genes that are activated late and that harbor classical ERE(s) or ARE(s) to which ER or AR directly bind, two molecules of SRC proteins, either as AIB1:SRC-1 or as AIB1:GRIP1, are recruited.

The pattern of the SRC family association with the promoter of the c-Myc gene, which is an early gene that does not contain a classical HRE, was totally different from that of the association of these proteins with the HRE-containing gene promoters described above. As shown in Figure 2, ChIP experiments detected only SRC-1 on the c-Myc gene promoter in T-47D cells (Fig. 2A, top) and in ECC-1 cells (Fig. 2B, top) in response to E2 stimulation, whereas GRIP1 was the only SRC protein detected on the c-Myc gene promoter in LnCAP cells in response to DHT stimulation (Fig. 2C, top). ChIP/Re-IP experiments confirmed the presence of only SRC-1 on the c-Myc gene promoter in T-47D cells (Fig. 2A, middle, bottom) and in ECC-1 cells (Fig. 2B, middle, bottom), and the presence of only GRIP1 on the c-Myc gene promoter in LnCAP cells (Fig. 2C, middle, bottom). The same pattern of SRC protein recruitment was also observed on the promoter of another non HRE-containing ER early target gene, insulin-like growth factor I (IGF-I; Umayahara et al. 1994; Shang and Brown 2002), in which the presence of only SRC-1 was detected in T-47D cells and in ECC-1 cells (data not shown). Taken together, these results indicate that, although on the HRE-containing promoter of genes that are activated late, two species of SRC proteins are recruited to coactivate transcription, whereas on the promoter of early 
A

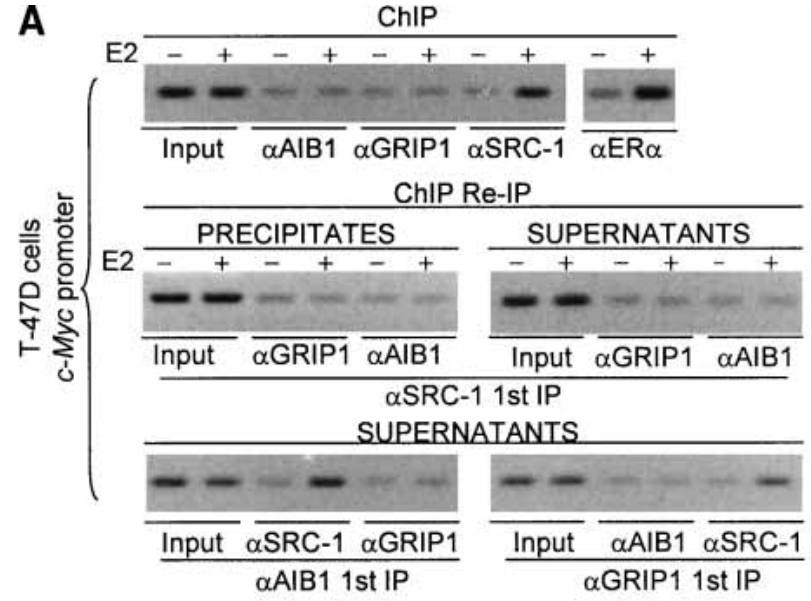

B
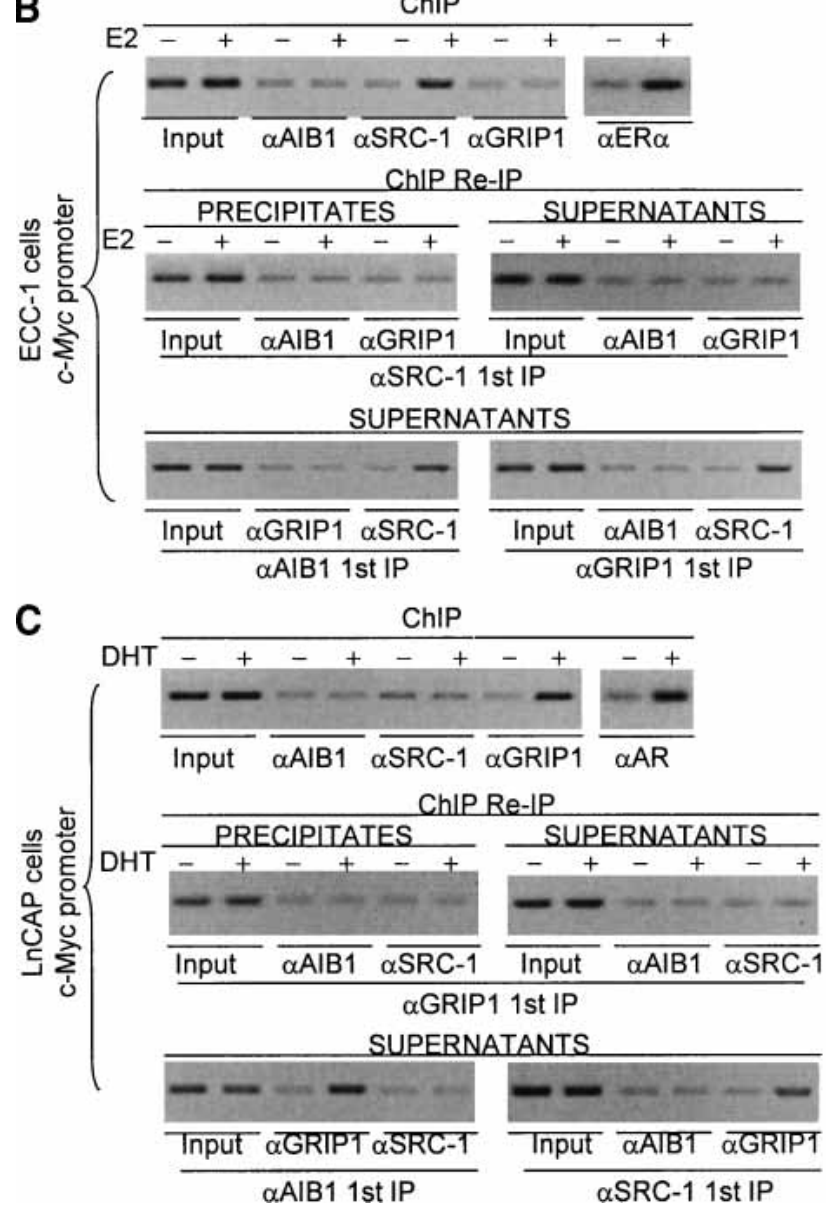

Figure 2. The pattern of recruitment of the members of the SRC family, SRC-1, GRIP1, and AIB1, on the promoters of the non-HRE-containing gene $c-M y c$ in T-47D cells $(A)$, ECC-1 cells $(B)$, and LnCAP cells $(C)$. Cells were grown in phenol red-free medium (DMEM for T-47D and ECC-1 and RPMI-medium 1640 for LnCAP cells) supplemented with $10 \%$ charcoal-dextranstripped FBS for at least $3 \mathrm{~d}$ and left untreated or treated with $100 \mathrm{nM}$ of E2 or $100 \mathrm{nM}$ of DHT for $45 \mathrm{~min}$ or $4 \mathrm{~h}$. ChIP assays and ChIP/Re-IP experiments were performed using specific antibodies against SRC-1, GRIP1, and AIB1. genes that do not contain classical HRE(s), SRC proteins act as a monomer. In our experiments, either SRC-1 or GRIP1, but not AIB1 was detected on the early gene promoters in the cell lines tested.

We then investigate whether the temporal gene activation is correlated to a timely coactivator recruitment. ChIP experiments demonstrated that at the time of $E B A G 9$ full activation and $c-M y c$ expression returning to the basal level $(\sim 4 \mathrm{~h}$ after E2 treatment in T-47D cells; Supplementary Fig. 1), no recruitment of SRC proteins was detected on $c-M y c$ promoter, whereas on EBAG9 promoter, the recruitment of SRC proteins was still detected (Fig. 3A), suggesting that the temporal gene activation is correlated to the coactivator recruitment. To determine the requirement for ER in E2-induced c-Myc expression and SRC protein recruitment, ER $\alpha$ expression was silenced by RNA interference (RNAi), and the expression of c-Myc and the recruitment of SRC-1 on the promoter of c-Myc gene were examined in ECC-1 cells. As shown in Figure 3B, silencing the expression of ER $\alpha$ rendered no significant stimulation of c-Myc expression by E2 and no recruitment of SRC-1 on the promoter of c-Myc gene, indicating that E2-induced c-Myc expression is dependent on $\mathrm{ER} \alpha$ and the recruitment of SRC-1 in ECC-1 cells. The $\beta$-actin gene expression was also measured as a control (see Supplementary Fig. 3). In addition, our previous experiments (Shang et al. 2000) and a recent report by others (Metivier et al. 2003) indicated that the coactivators could be recruited to gene promoters in a timely fashion. To investigate whether or not the differential recruitment of SRC proteins on different gene promoters was a reflection of the SRC protein recruitment on a specific time point, a time course ChIP experiment was performed for the recruitment of SRC coactivators as well as p300 and CARM1 on c-Myc and EBAG9 gene promoter in ECC-1 cells. As shown in Figure $3 \mathrm{C}$, the recruitment of AIB1, GRIP1, and SRC-1 was similar timewise on EBAG9 gene promoter, whereas the recruitment of only SRC-1 was detected on the c-Myc gene promoter, suggesting that the observed differential recruitment of SRC proteins was not due to the time point selected. A time course recruitment of p300 and CARM1 was also examined and the data showed that there was no apparent difference in p300 recruitment on the promoter of early versus late gene, whereas the time for CARM1 occupancy on late gene promoter was longer (Fig. 3C).

We next tested the hypothesis that the corecruitment of AIB1 and SRC-1 or AIB1 and GRIP1 on HRE-containing promoters might involve a protein heterodimerization between these two molecules and not merely a coassociation of these proteins. For this purpose, we utilized the reversed pharmacology of the GRIP1 protein called subGRIP1. As we reported earlier (Shang et al. 2000), subGRIP1 harbors nuclear corepressor-binding motifs (CoRNR boxes) instead of nuclear receptor-binding motifs (NR boxes). As such, subGRIP1 is capable of binding to helix 12-deleted RXR and antagonist-bound steroid receptors and is sufficient to coactivate target gene transcription in the presence of the antagonists (Shang et al. 
2000, 2002). As stated earlier, the SRC proteins contain a nuclear receptor interacting domain, a CBP/p300 interacting domain, as well as a domain near the $\mathrm{C}$ terminus that has been shown to be able to interact with proteins that have methyltransferase activities (Chen et al. 2000; Koh et al. 2001). In the $\mathrm{N}$ terminus, SRC proteins contain a bHLH domain and a PAS domain known to be involved in protein-protein dimerization/interaction. Thus, we created mutations in subGRIP1 with deletion of either the bHLH domain (subGRIP1 $\mathrm{bHLH}$ ), the PAS domain (subGRIP1 $\triangle$ PAS), or both the bHLH and the PAS domains (subGRIP1 $\Delta$ bHLH + PAS; Fig. 4A). We then tested the effects of these mutants on ER-mediated transcription after treatment with tamoxifen, an ER antagonist. We reasoned that if a dimerization is needed between SRC proteins in ER-mediated transcription of

A
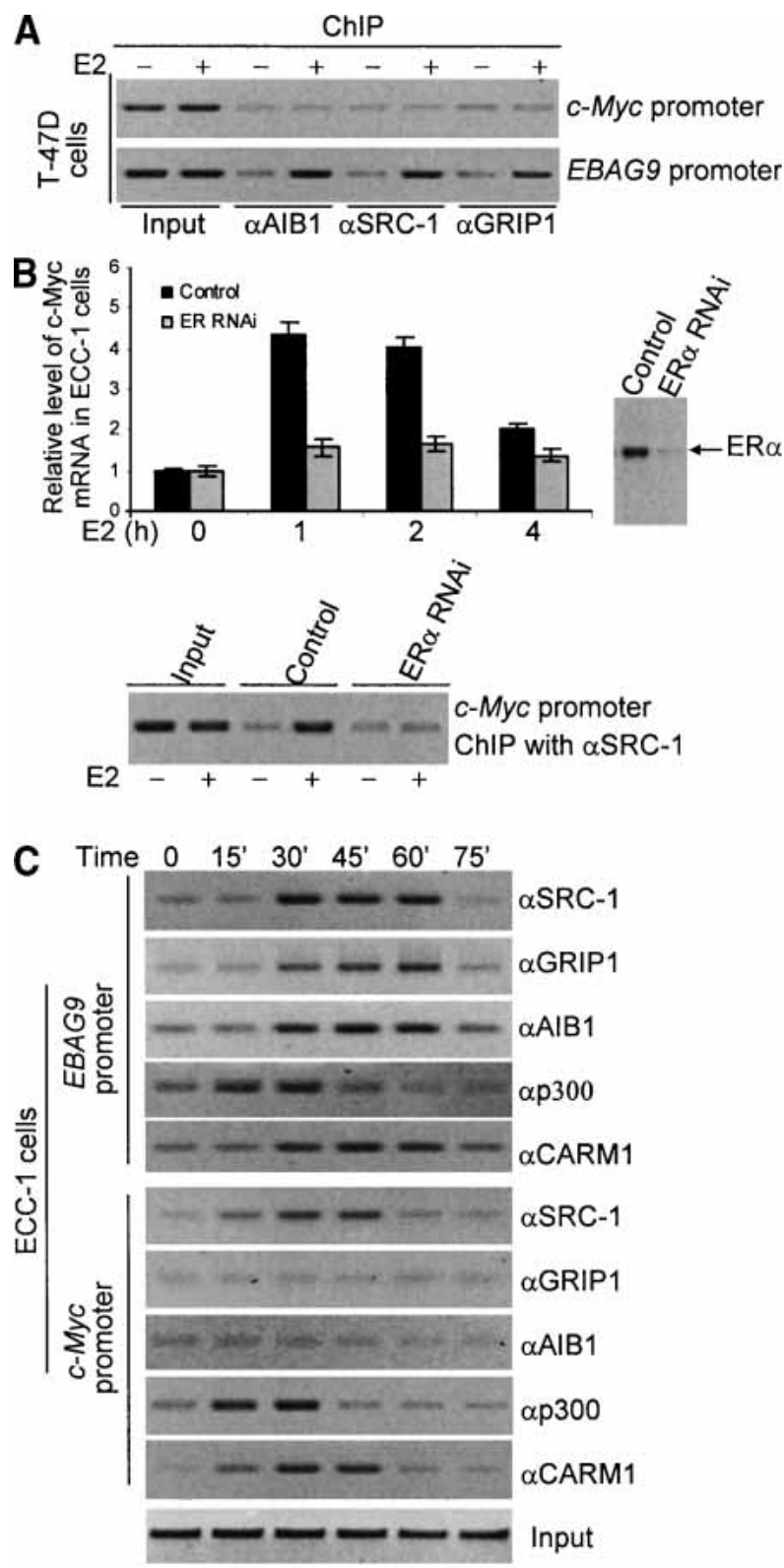

HRE-containing genes and the dimerization occurs through the bHLH and/or PAS domain, the subGRIP1 mutants will no longer be able to coactivate the transcription of these genes. In these experiments, T-47D cells were transfected with either subGRIP1 $\Delta \mathrm{bHLH}$, subGRIP1 $\Delta$ PAS, or subGRIP1 $1 \mathrm{bHLH}+\mathrm{PAS}$, and then treated with a saturating level of tamoxifen for different periods of time. The expression of c-Myc and EBAG9 genes was measured by real-time RT-PCR. As shown in Figure 4B, although all of the mutants of subGRIP1 had minimal effect on tamoxifen-stimulated $c$-Myc expression, deletion of either the bHLH domain (bHLH del) or the PAS domain (PAS del) resulted in a decreased EBAG9 expression, although the effect of the PAS domain deletion was greater, indicating that both bHLH and PAS domains are necessary, but not sufficient in gene coactivation. In supporting this notion, the bHLH and PAS double-deletion (bHLH + PAS del) resulted in a diminished gene coactivation. ChIP analyses showed that, on c-Myc gene promoter, GRIP1 was the only SRC coactivator recruited in all subGRIP-, subGRIP1 $\triangle$ bHLH-, subGRIP1 $\triangle$ PAS-, and subGRIP1 $\Delta$ bHLH + PAS-transfected cells, whereas on EBAG9 promoter, although consistent levels of GRIP1 recruitment was observed in all subGRIP1-, subGRIP1 $\Delta$ bHLH (bHLH del)-, subGRIP1 $\triangle$ PAS (PAS del)-, and subGRIP1 $\Delta$ bHLH + PAS-transfected cells, the recruitment of AIB1 was much weaker in subGRIP1 $1 \mathrm{bHLH}$ (bHLH del)- and subGRIP1 $\triangle$ PAS (PAS del)-transfected cells and was diminished in subGRIP1 $1 \mathrm{bHLH}+\mathrm{PAS}$ transfected cells (Fig. 4C). The expression of the subGRIP1 and its mutants was verified by Western blotting in Figure 4D. These experiments further support the observations that SRC proteins function on the c-Myc gene as a monomer, but that two species of the SRC proteins

Figure 3. (A) The coactivator recruitment on c-Myc and EBAG9 gene promoters in T-47 cells after treatment with E2 for $4 \mathrm{~h}$. T-47D cells were grown in phenol red-free DMEM supplemented with $10 \%$ charcoal-dextran-stripped FBS for at least $3 \mathrm{~d}$, and left untreated or treated with $100 \mathrm{nM}$ of E2 for $4 \mathrm{~h}$. ChIP assays were performed using specific antibodies against SRC-1, GRIP1, and AIB1. (B) ER-dependency of c-Myc expression and the recruitment of SRC-1 to the c-Myc gene promoter. ECC-1 cells were seeded in phenol red-free medium supplemented with 10\% charcoal-dextran-stripped FBS. Twenty-four hours later, cells were transfected with pSUPER constructs containing specific sequences for ER $\alpha$ mRNAs. Forty-eight hours after transfection, cells were treated with $100 \mathrm{nM}$ of $\mathrm{E} 2$ for different periods of time. Cells were then collected and total RNA was extracted for c-Myc mRNA analysis by real-time RT-PCR. The effect of RNAi on the ER $\alpha$ expression was examined by Western blotting. ChIP experiments were performed for the SRC-1 recruitment on c-Myc gene promoter after treatment of the transfected ECC-1 cells with E2 for $45 \mathrm{~min}$. (C) The time course experiments for the coactivator recruitment on the ER target gene promoters in ECC-1 cells. ECC-1 cells were grown in phenol red-free DMEM supplemented with $10 \%$ charcoal-dextranstripped FBS for at least $3 \mathrm{~d}$, and left untreated or treated with $100 \mathrm{nM}$ of E2 for different periods of time. ChIP assays were performed using specific antibodies against SRC-1, GRIP1, AIB1, p300, and CARM1. 
Figure 4. The involvement of bHLH and PAS domains in the differential recruitment of SRC coactivators. (A) Schematic diagram of the generation of subGRIP1 mutations. (bHLH) Basic helix-loop-helix; (PAS) PerArnt-Sim; (NR box) nuclear receptor-binding motifs; (CoRNR box) corepressor nuclear receptor-binding motifs. $(B)$ The effect of subGRIP1 mutations on their coactivation of cMyc and EBAG9 gene expression in T-47D cells after treatment with $1 \mu M$ 4-hydroxytamoxifen (Sigma). T-47D cells were seeded in DMEM medium supplemented with 10\% FBS. Twenty-four hours later, cells were transfected with either vector, subGRIP1, subGRIP1 1 bHLH, subGRIP1 $\triangle$ PAS, or subGRIP1 $1 \mathrm{bHLH}+\mathrm{PAS}$ for $5 \mathrm{~h}$ before switching to phenol red-free medium. Fortyeight hours after transfection, cells were collected and total RNA was extracted using TRIZOL Reagent. Expression of c-Myc and EBAG9 mRNA was measured by realtime RT-PCR. (C) ChIP analysis of SRC coactivator recruitment in subGRIP1 and its mutants-transfected T-47D cells. T-47D cells were seeded in DMEM medium supplemented with $10 \%$ FBS. Twenty-four hours later, cells were transfected with either vector, subGRIP1, subGRIP1 $\triangle \mathrm{bHLH}$, subGRIP1 $\triangle$ PAS, or subGRIP1 $\triangle$ bHLH + PAS for $5 \mathrm{~h}$ before switching to phenol red-free medium. Forty-eight hours after transfection, ChIP assays were performed using specific antibodies against GRIP1 and AIB1. (D) Western blotting analysis of the protein expression. T-47D cells were seeded in DMEM medium supplemented with $10 \%$ FBS. Twenty-four hours later, cells were transfected with either vector, subGRIP1, subGRIP1 $\triangle \mathrm{bHLH}$, subGRIP1 $\mathrm{PAAS}$, or subGRIP1 $\triangle \mathrm{bHLH}+\mathrm{PAS}$ for $5 \mathrm{~h}$ before switching to phenol red-free medium. Fortyeight hours after transfection, cells were collected, and cellular proteins were extracted for Western blotting analysis with antibodies against GRIP1. Transfection efficiency was monitored by cotransfection with an E. coli lacZ construct (pcDNA4/His/Max/lacZ, Invitrogen Corp.).

participate in coactivating the EBAG9 gene. More importantly, these experiments strongly favor a molecular module, in which two members of the SRC family act through their interaction via bHLH and PAS domains on the EBAG9 gene promoter.

Our previous study (Shang and Brown 2002) demonstrated that a higher level of SRC-1 expression in endometrial cells contributed to the agonistic activity of tamoxifen-liganded ER that otherwise exerts antagonism in mammary tissue, which is the basis for the use of tamoxifen in treatment of breast cancer. To explore the molecular basis for the differential recruitment of SRC proteins on the different target gene promoters, we first assessed by Western blotting the level of expression of SRC-1, GRIP1, and AIB1 proteins in the cells tested above. As shown in Figure 5A, whereas the expression level of AIB1 was similar in T-47D, ECC-1, and LnCAP cells, the expression level of SRC-1 was higher in T-47D and ECC-1 cells, and the expression level of GRIP1 was higher in LnCAP cells. It appeared that the higher expression of a particular SRC protein is linked to the association of this protein with the non-HRE-containing gene promoters described in Figure 2. That is, in T-47D and ECC-1 cells, in which the highest expression of the SRC protein is SRC-1, the promoter-associated SRC protein is also SRC-1; likewise, in LnCAP cells, in which the highest expression of the SRC protein is GRIP1, the promoter-associated SRC protein is also GRIP1.

To test the hypothesis that the higher expression of a particular SRC protein over other SRC proteins could determine the participation of the protein in gene-transcription activation, we first sought to assess the contribution of SRC-1, GRIP1, and AIB1 in temporal coactiva- 
A

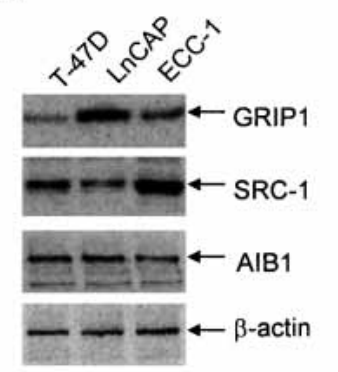

C
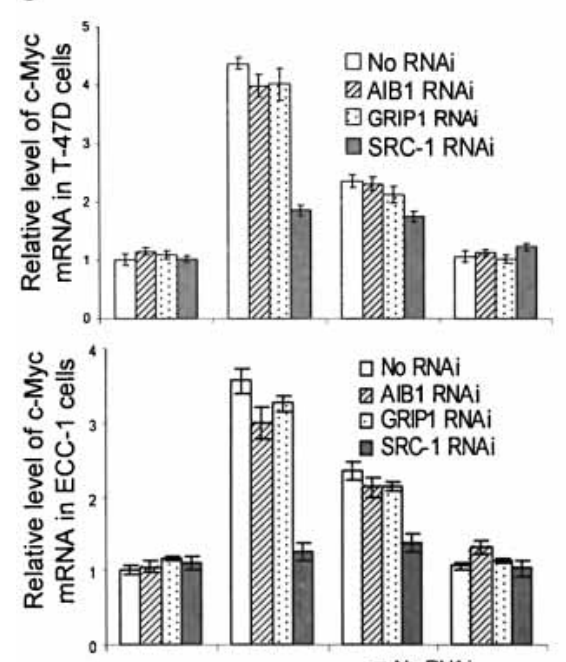

再

Q ABIP1 RNAi

SRC-1 RNAi

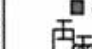

耳-
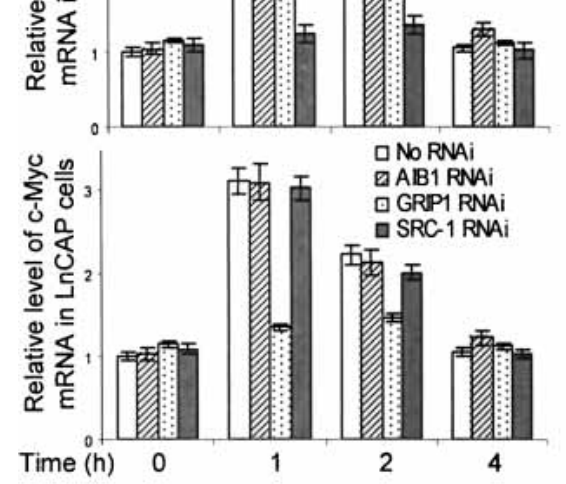
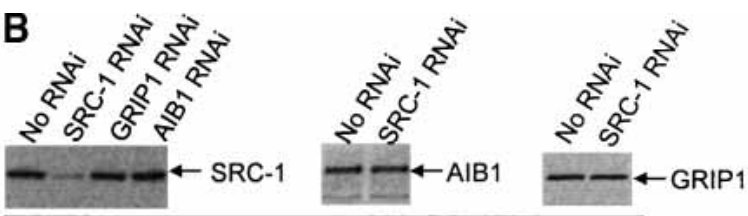

$\mathrm{ECC}$

CC-1 cells
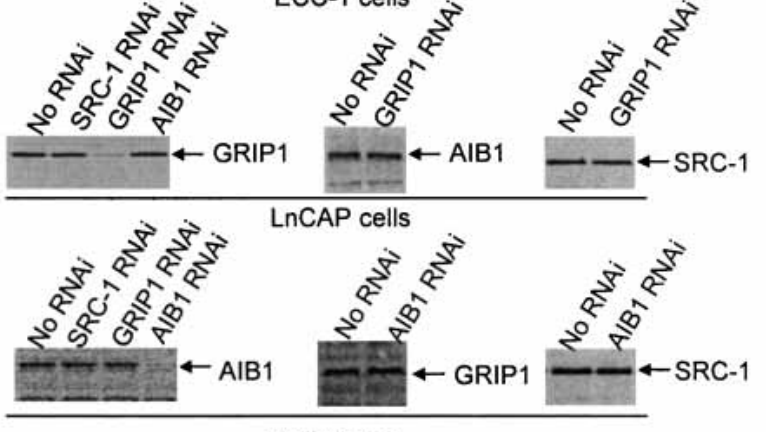

T-47D cells
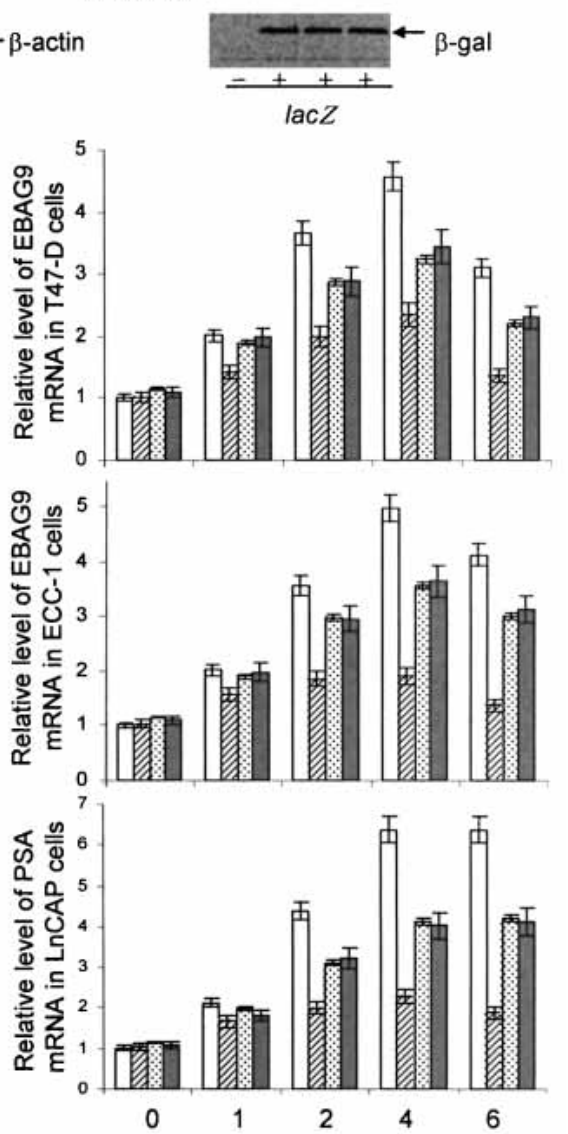

Figure 5. Differential coactivation of gene transcription by members of SRC family. (A) Western blotting measurement of the expression of SRC-1, GRIP1, and AIB1 in T-47D, ECC-1, and LnCAP cells. Cells were grown in normal culture medium (DMEM for T-47D and ECC-1 and RPMI-medium 1640 for LnCAP cells) supplemented with $10 \%$ FBS to $95 \%$ confluence. Cellular proteins were extracted, and the expression of SRC-1, GRIP1, and AIB1 was measured by Western blotting. $(B)$ Western blotting measurement of the expression of SRC-1, GRIP1, and AIB1 in T-47D, ECC-1, and LnCAP cells after RNAi. Cells were seeded in normal culture medium (DMEM for T-47D and ECC-1 and RPMI-medium 1640 for LnCAP cells) supplemented with $10 \%$ FBS. Twenty-four hours later, cells were transfected with pSUPER constructs containing specific sequences for mRNAs of SRC-1, GRIP1, or AIB1. Forty-eight hours after transfection, cells were collected, and cellular proteins were extracted for Western blotting analysis. Transfection efficiency was monitored by cotransfection with the E. coli lacZ construct. $(C)$ The effect of silencing the expression of SRC-1, GRIP1, and AIB1 by RNAi on their coactivation of c-Myc gene expression in different cells. Cells were seeded in phenol red-free medium (DMEM for T-47D and ECC-1 and RPMI-medium 1640 for LnCAP cells) supplemented with $10 \%$ charcoal-dextranstripped FBS. Twenty-four hours later, cells were transfected with pSUPER constructs containing specific sequences for mRNAs of SRC-1, GRIP1, or AIB1. Fortyeight hours after transfection, cells were collected, and total RNA was extracted using TRIZOL Reagent. Expression of c-Myc mRNA was measured by real-time RTPCR. tion of ER- or AR-mediated transcription. In these experiments, the expression of SRC-1, GRIP1, or AIB1 was inhibited by RNAi, and the expression of the ER or AR target genes was measured by real-time RT-PCR. As shown in Figure 5C, in both T-47D and ECC-1 cells, where SRC-1 expression is higher and SRC-1 is the only SRC protein detected on the c-Myc gene promoter, inhibition of SRC-1 expression by RNAi (Fig. 5B) led to a significant decrease in $c-M y c$ expression, whereas the effect of either GRIP1 or AIB1 inhibition on $c$-Myc expres- sion was minimal. In contrast, for the late genes whose promoters contain classical HRE(s) (EBAG9 in T-47D cells and PSA in LnCAP cells), the greatest effect on their expression was seen when the expression of AIB1 was inhibited, whereas the effect of either SRC-1 or GRIP1 inhibition was somewhat smaller. On the other hand, in LnCAP cells, where GRIP1 expression is higher and GRIP1 is the only SRC protein detected on the c-Myc gene promoter, inhibition of GRIP1 expression resulted in a profound decrease in $c-M y c$ expression, whereas the 
effect of either SRC-1 or AIB1 inhibition was minimal. Collectively, these results are consistent with the recruitment pattern of SRC-1, GRIP1, and AIB1 on the target gene promoters described in Figures 1 and 2, supporting the model that, on late genes whose promoter contains HRE(s), SRC proteins coactivate transcription through possible formation of either AIB1:GRIP1 or AIB1:SRC-1 dimers, whereas on non-HRE-containing early gene promoters, GRIP1 or SRC-1 act as a monomer. These data also strongly favored the notion that the higher expression level of SRC-1 or GRIP1 contributes to their participation, and thus, coactivation of transcription in a particular cell.

To further solidify this argument, as well as to ask the question whether the recruitment of SRC-1 or GRIP1 on non-HRE-containing promoters is merely a result of the level of their expression or a reflection of their intrinsic specifications, we first examined the role of AIB1 in cMyc gene expression and the promoter recruitment of AIB1 on the c-Myc gene in other ER-positive mammary carcinoma cell lines (MCF-7 and ZR-75-1), in which the AIB1 gene is amplified and overexpressed (Anzick et al. 1997). We reasoned that, if the participation and coactivation of the non-HRE-containing genes by a SRC protein is linked to its higher level of expression, then AIB1 should be involved in c-Myc gene transactivation in these cells. As shown in Figure 6A (left), the expression level of AIB1 in both MCF-7 cells and ZR-75-1 cells was much higher than that in T-47D cells. ChIP experiments demonstrated that, in addition to the association of SRC1, AIB1 was also present on the promoter of the c-Myc gene in both MCF-7 and ZR-75-1 cells (Fig. 6A, right). This is in contrast to the results in T-47D cells, in which only SRC-1 was present on the c-Myc gene promoter (Fig. 2A, top). ChIP/Re-IP experiments demonstrated that AIB1 acts as a monomer in these cells rather than as a possible dimer with SRC-1, as SRC-1 was only found in the supernatants, but not in the immunoprecipitates from the first immunoprecipitation with antibodies against AIB1 (Fig. 6A, right). The same was true for SRC1. RNAi experiments demonstrated that, both in MCF-7 cells and in ZR-75-1 cells, inhibition of the expression of either AIB1 or SRC-1 resulted in a decreased expression of the c-Myc gene, whereas the effect of the inhibition of GRIP1 expression was negligible (Fig. 6B). This is consistent with the recruitment pattern of the SRC proteins (Fig. 6A, right). In addition, c-Myc gene expression was almost totally abolished in ZR-75-1 cells with an AIB1 and SRC-1 double-knockdown (Fig. 6D). These results strongly suggest that the level of expression of SRC proteins is sufficient in determining the participation of a specific coactivator on a non-HRE-containing early gene.

To further support the idea that the recruitment of a particular SRC protein on a non-HRE-containing early gene promoter is due to the higher expression of the protein, we next generated stable ECC-1 cells with SRC-1 expression inhibited by RNAi. We then overexpressed GRIP1 or AIB1 in these cells, and the expression of cMyc gene was measured. As shown in Figure 6C, overexpression of either GRIP1 or AIB1 led to an elevated expression of the c-Myc gene. Collectively, these data indicate that the utilization of a SRC protein in coactivating non-HRE-containing early genes is determined by the concentration of the particular SRC protein.

As stated before, AIB1 amplification and/or overexpression is a common observation in primary breast cancer (Anzick et al. 1997; Bautista et al. 1998). However, whether or how such genetic/epigenetic alterations are associated with breast cancer carcinogenesis is not understood. Analogously, $c-M y c$ amplification/overexpression has also been documented in $\sim 30 \%$ of breast carcinomas (Guerin et al. 1988; Bieche et al. 1999; Chrzan et al. 2001; Naidu et al. 2002). In light of our observation that overexpression of AIB1 led to an increased level of $c-M y c$ expression, it is logical to postulate that the amplification/overexpression of c-Myc may be linked to the amplification/overexpression of AIB1 in primary breast carcinomas. To validate this hypothesis, we collected $\mathrm{ER}^{+}(n=76)$ and $\mathrm{ER}^{-}(n=38)$ breast tumor samples from breast cancer patients for whom complete information on clinical tumor size, nodal status, and ER status was available. The expression of $A I B 1$ and $c-M y c$ mRNAs was analyzed by real-time RT-PCR in these samples. The relative level of $A I B 1$ expression is plotted against the relative level of $c-M y c$ expression (GAPDH expression was measured as the internal control). Statistical analysis with the SAS system found a Spearman correlation coefficient of $0.70661(P<0.0001)$ and a Kendall Tau b correlation coefficient of $0.52279(P<0.0001)$, indicating a strong positive correlation between the expression of $A I B 1$ and the expression of $c-M y c$ in the $\mathrm{ER}^{+}$ breast carcinomas, whereas in $\mathrm{ER}^{-}$breast carcinomas, there was no clear correlation (Fig. 7A).

It would be important to examine whether increased expression of the c-Myc gene is due to genetic amplification or results from overexpression in particular tumor samples. A genetically amplified c-Myc gene should bypass the ER and AIB1 requirements, and thus, there would be no expected correlation with AIB1 levels. We examined three $\mathrm{ER}^{+}$tumor samples with high $c$-myc expression and low AIB1 expression. In these samples, $c$ $m y c$ gene was found to be amplified. We also examined three $\mathrm{ER}^{+}$tumor samples with high $c$-myc expression and high $A I B 1$ expression. In these samples, $c$-myc gene was not amplified (data not shown). These results strongly support our conclusion that AIB1 overexpression contributes to the higher level of c-Myc in breast cancers.

\section{Discussion}

\section{Differential recruitment pattern of SRC family in ER-and AR-mediated transcription}

The phenotypes of the gene knockout mice for $S R C-1$ (Xu et al. 1998), AIB1 (Wang et al. 2000; Xu et al. 2000) and GRIP1 (Gehin et al. 2002) have shown that the SRC family is not only required for the normal development of the reproductive system, but is also important in the 
A

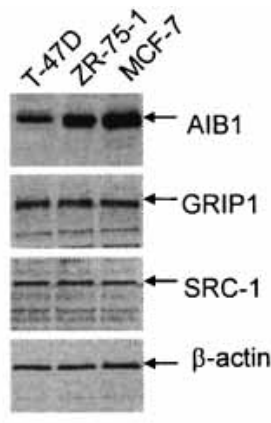

B

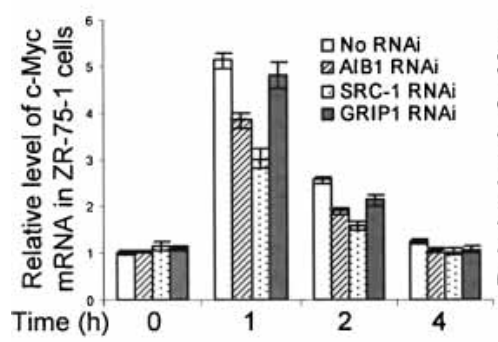

C

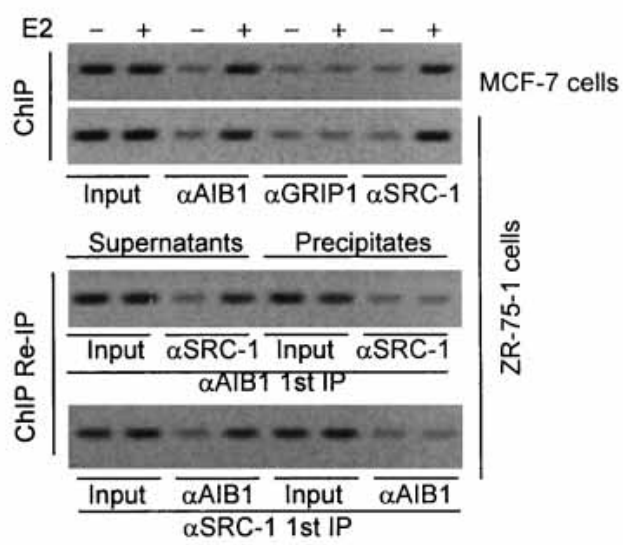

Figure 6. Coactivation of $c-M y c$ expression by the members of the SRC family in different cells. $(A)$ Western blotting analysis of the expression of AIB1, GRIP1, and SRC-1 in T-47D, ZR-75-1, and MCF-7 cells (left), and ChIP assays and ChIP/Re-IP analyses of the recruitment of SRC-1, GRIP1, and AIB1 on the promoter of the c-Myc gene in different cells (right). Cells were grown in DMEM supplemented with $10 \%$ FBS for $48 \mathrm{~h}$, and cell proteins were extracted for protein analysis. For ChIP assays and ChIP/Re-IP analyses, cells were grown in phenol red-free DMEM medium supplemented with $10 \%$ charcoal-dextran-stripped FBS for at least $3 \mathrm{~d}$, and left untreated or treated with $100 \mathrm{nM}$ of E2 for $45 \mathrm{~min}$. ChIP assays and ChIP/Re-IP experiments were performed using specific antibodies against SRC-1, GRIP1, and AIB1. (B) The effect of silencing the expression of SRC-1, GRIP1, and AIB1 on the coactivation of the c-Myc gene in ZR-75-1 and MCF-7 cells. Cells were seeded in phenol red-free DMEM supplemented with $10 \%$ charcoal-dextranstripped FBS. Twenty-four hours later, cells were transfected with pSUPER constructs containing specific sequences for mRNAs of SRC-1, GRIP1, or AIB1. Forty-eight hours after transfection, cells were collected and total RNA was extracted using TRIZOL Reagent. Expression of $c-M y c$ mRNA was measured by real-time RT-PCR. (C) The effect of GRIP1 or AIB1 overexpression on the $\mathrm{c}-\mathrm{Myc}$ gene coactivation by GRIP1 and AIB1 in SRC-1 expression stably silenced ECC-1 cells. ECC-1 cells with SRC-1 expression stably silenced were generated by RNAi and were seeded in phenol red-free DMEM supplemented with 10\% charcoal-dextran-stripped FBS. Twenty-four hours later, cells were transfected with a GRIP1 expression construct or an AIB1 expression construct. Forty-eight hours after transfection, cells were collected and total RNA was extracted using TRIZOL Reagent and the expression of $c-M y c$ mRNA was measured (bottom). The overexpression of GRIP1 and AIB1 was confirmed by Western blotting analyses (top). (D) The effect of double "knockdown" of SRC-1, GRIP1, and AIB1 on the coactivation of the c-Myc gene in ZR-75-1 cells. Cells were seeded in phenol red-free DMEM supplemented with $10 \%$ charcoal-dextran-stripped fetal bovine serum. Twenty-four hours later, cells were transfected with pSUPER constructs containing specific sequences for mRNAs of SRC-1, GRIP1, or AIB1. Forty-eight hours after transfection, cells were collected and total RNA was extracted using TRIZOL Reagent. Expression of c-Myc mRNA was measured by real-time RT-PCR (bottom). The effect of RNAi on the expression of SRC-1, GRIP1, and AIB1 was confirmed by Western blotting (top).

development of other systems. Along with the amplification/overexpression of AIB1 in primary breast/ovarian cancers (Anzick et al. 1997; Bautista et al. 1998), and GRIP1-MOZ fusion in human acute myeloid leukaemia (Carapeti et al. 1998), the importance of the SRC family extends to the maintenance of normal physiology. These observations are also an indication of functional specificities for members of the SRC family. However, such specificities have been difficult to demonstrate at the molecular level. Although different selectivities for dif- ferent members of the SRC family have been reported for different types/isotypes of nuclear receptors and other transcription factors (Kraichely et al. 2000; Issa et al. 2001; Barkhem et al. 2002; Beischlag et al. 2002; Bommer et al. 2002), most in vitro studies and transfection experiments have demonstrated that each member of the SRC family is capable of interaction with multiple nuclear receptors, and that a particular nuclear receptor is able to interact with all three members of the SRC family. We demonstrated here that there is a concerted 
Zhang et al.

Figure 7. (A) Correlation between the expression of c-Myc and AIB1 in breast tumor samples. Freshly removed breast cancer tissue samples were frozen in liquid nitrogen immediately after surgical removal and maintained at $-80^{\circ} \mathrm{C}$ until use for RNA extraction. Total RNA was extracted using TRIZOL Reagent and the expression of $c-M y c$ and AIB1 mRNA was measured by real-time RT-PCR. The relative level of AIB1 expression was plotted against the relative level of $c-M y c$ expression with GAPDH expression as the reference. $(B)$ Model of differential gene regulation by the SRC family coactivators. On classical HRE-containing late gene promoters, one pair of SRC proteins are recruited with either SRC-1 or GRIP1 possibly partnered with AIB1, whereas on the promoter of early genes that lack a classical HRE, SRC proteins are recruited as a monomer. (HRE) Hormone responsive element; $(\mathrm{R})$ receptor.

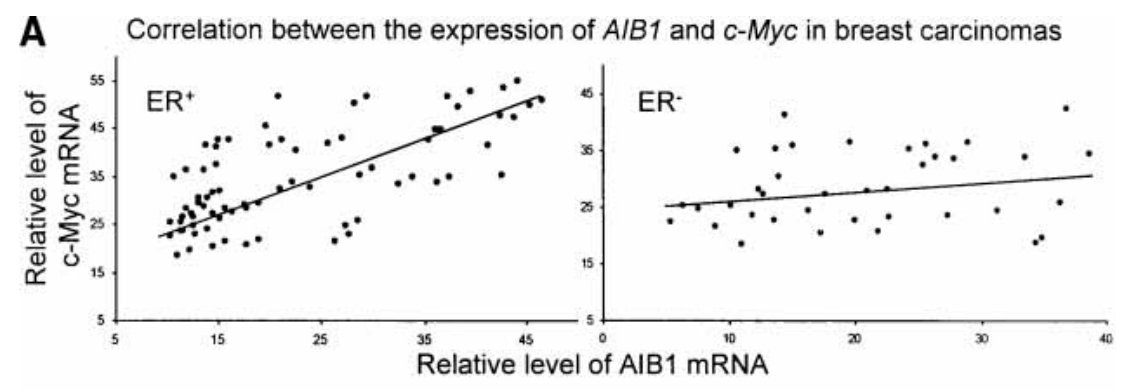

\begin{tabular}{cccccc}
\hline Genes & $N$ & Mean & Std Dev & Median \\
\cline { 2 - 6 } ER $^{+}$ & AlB1 & 76 & 21.00526 & 11.31259 & 14.96000 \\
& $c-M y c$ & 76 & 34.92079 & 11.06087 & 32.90000 \\
\cline { 2 - 5 } ER- & AlB1 & 38 & 20.49144 & 9.40491 & 19.80500 \\
& $c-M y c$ & 38 & 28.34004 & 6.50942 & 27.24177 \\
\hline
\end{tabular}

B

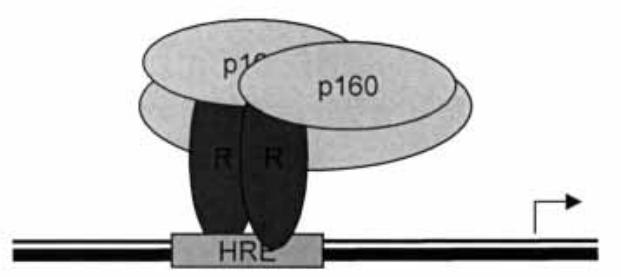

Late genes (EBAG9, PSA, etc.)

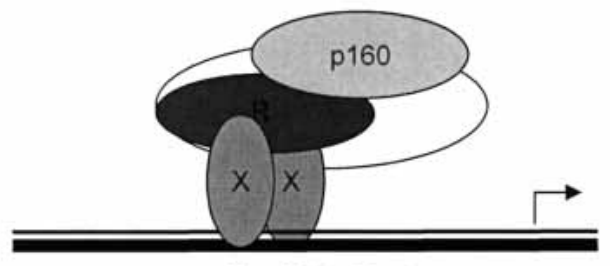

Early genes (c-Myc, IGF-I, etc.) recruitment pattern for the SRC proteins in ER- and ARmediated transcription. Specifically, it was shown that, on classical HRE-containing late gene promoters, one pair of SRC proteins is recruited with either SRC-1 or GRIP1, possibly partnered with AIB1, whereas on the promoter of early genes that lack a classical HRE, SRC proteins are recruited as a monomer (Fig. 7B).

It is unclear what makes AIB1 a possible common dimerization partner for SRC-1 and GRIP1, as there are no identifiable distinctions in the structure and functional domains among members of the SRC family. Nonetheless, dimerization between SRC proteins has long been speculated because of the existence of proteinprotein dimerization/interaction domains in these proteins. Using a chimeric GRIP1 protein and its mutants, we showed that these two domains are required for coactivation of EBAG9, an HRE-containing gene, by the SRC proteins, supporting the observations that two different molecules from the SRC family participate in the coactivation of these genes, and that these two domains are involved in SRC dimerization in vivo. However, an alternative possibility still exists that interactions may occur through coactivators such as CoCoA (Kim et al. 2003).
It is puzzling why both AIB1:SRC-1 and AIB1:GRIP1 pairs are recruited on the promoter of the same gene, as this raises a question of functional redundancy for SRC-1 and GRIP1. However, our results are consistent with the previous observation that there is a compensatory upregulation of GRIP1 expression in SRC-1 knockout mice in reproductive organs such as uterus, prostate, testis, and mammary gland (Xu et al. 1998). Another obvious, but unanswered question, is why transactivation of classical HRE-containing late genes needs two molecules of the SRC family. A transcription complex in ER- or ARmediated transcription contains receptor dimer(s), general coactivators, SRC proteins, and methyltransferases, as well as other coactivators and mediators (Lemon and Freedman 1999; Glass and Rosenfeld 2000; Shang et al. 2000, 2002; Rachez and Freedman 2001). Along with the basal transcription machinery, the transcription edifice is already complex enough. The rate-limiting step in transcription is transcription initiation and, thus, it is only a speculation that the complexity of transcription initiation calls for a complicated transcription complex, which, in turn, needs additional factors to build and to support. Among these factors, SRC family are pivotal, at least in ER-mediated transcription, as we reported earlier 
(Shang et al. 2000). Finally, a direct interaction between SRC coactivators was not detected by in vitro GST pulldown and in vivo IP experiments. However, such a stable complex may only exist in vivo in the context of a chromatin structure, in which case, the detection is beyond the capability of current methodologies.

\section{The mechanism of differential gene regulation by SRC family}

Contrary to the classical HRE-containing late gene promoters, the SRC family is recruited on non-HRE-containing early gene promoters as a monomer. The recruitment of a particular member of the SRC family appears to be determined by the level of expression of the particular protein. Although AIB1, acting as a common partner with SRC-1 and GRIP1 on HRE-containing promoters, is not recruited on non-HRE-containing promoters in the cells we tested, overexpression of AIB1 could lead to its recruitment and transcription activation in these cells.

The observation that AIB1 is involved in the transactivation of non-HRE-containing genes such as $c-M y c$ in cells with AIB1 amplification and overexpression is interesting. As stated before, AIB1 has been found to be amplified/overexpressed in $64 \%$ of primary breast cancers as well as in some primary ovarian tumors (Anzick et al. 1997; Bautista et al. 1998). However, whether and how this genetic/epigenetic change in the AIB1 gene is in any way associated with breast cancer carcinogenesis is not understood. It is intriguing to speculate that AIB1 overexpression could lead to the coactivation of genes such as $c-M y c$, which is normally only coactivated by SRC-1 in mammary tissue. In this context, it is worthy to note that $c-M y c$ overexpression is commonly found in breast/prostate carcinomas (Guerin et al. 1988; Bieche et al. 1999; Chrzan et al. 2001; Naidu et al. 2002), and c$M y c$ has been implicated in cell growth, proliferation, apoptosis, and malignant transformation, including breast cancer carcinogenesis (D'Cruz et al. 2001; Nasi et al. 2001; Yu et al. 2001).

Steroid receptors such as ER and AR target different sets of genes or classes of genes. Some genes, such as $c-M y c$, are early genes that are activated quickly; others, such as EBAG9 and PSA, are activated later. Mechanisms must have evolved to produce precise temporal regulation of transcription. It is clear that one of the mechanisms is ER indirect binding to the promoter of early genes. By binding to other transcription factors instead of assembling itself on DNA, ER or AR could conveniently add itself to a possibly preformed transcription complex and thereby readjust the rate of transcription. In this case, the selection for association of a SRC protein with ER or AR could also be conveniently determined by the abundance of a particular member of the SRC family. On the other hand, the activation of HRE-containing genes needs assembly of a new transcription complex with receptor binding to DNA first. Such a process needs more factors and takes a longer time, and thus, two members of the SRC family are recruited and transcrip- tion occurs later. In this regard, it is conceivable that a mechanism has evolved to maintain a balanced abundance of SRC proteins inside a cell to sustain the precise temporal regulation of transcription. Future investigations are needed to elucidate this mechanism.

\section{Materials and methods}

\section{Western blotting}

Total cellular protein was separated on $7.5 \%$ SDS-PAGE and transferred to nitrocellulose membranes, which were then incubated with primary antibodies. After adding appropriate secondary antibodies, the blots were developed using an ECL kit (Amersham). Antibodies used in this experiment were $\alpha$ AIB1 (affinity-purified rabbit polyclones), $\alpha$ GRIP1 (affinity-purified rabbit polyclones), $\alpha$ SRC-1 (a mouse monoclone), and anti- $\beta$ galactosidase (a mouse monoclone).

\section{ChIP}

The ChIP experiments were performed essentially the same as described previously (Shang et al. 2000, 2002; Shang and Brown 2002). The primers for ChIP were c-Myc (-95 to -245$)$ forward primer (AGGCGCGCGTAGTTAATTCAT) and c-Myc reverse primer (CGCCCTCTGCTTTGGGA); IGF-I (-111 to -312) forward primer (TTGTCACCATGCCCAAAAAA) and IGF-I reverse primer (TTGCGCAGGCTCTATCTGC); PSA (-39 to -250) forward primer (TCTGCCTTTGTCCCCTAGAT) and PSA reverse primer (AACCTTCATTCCCCAGGACT); and EBAG9 $(-182$ to +72$)$ forward primer (ATTGTCTGCCCTTC GCCGT) and EBAG9 reverse primer (TTTGGAGGCTGCGT GCTTT).

\section{ChIP/Re-IP}

$\mathrm{ChIP} / \mathrm{Re}$-IPs on supernatants were done essentially the same as primary IPs. Bead eluates from the first immunoprecipitation were incubated with $10 \mathrm{mM}$ DTT at $37^{\circ} \mathrm{C}$ for $30 \mathrm{~min}$ and diluted 1:50 in dilution buffer (1\% Triton X-100, 2 mM EDTA, $150 \mathrm{mM} \mathrm{NaCl}, 20 \mathrm{mM}$ Tris- $\mathrm{HCl}$ at $\mathrm{pH} 8.1$ ) followed by reimmunoprecipitation with the second antibodies.

\section{Construction of subGRIP1 mutants}

The construction of a CoRNR box-containing GRIP1 (subGRIP1) has been described elsewhere (Shang et al. 2000). subGRIP1 mutants were created by PCR with subsequent ligation of the $\mathrm{N}$-terminal fragment and the C-terminal fragment. The PCR primers for creating subGRIP1 $1 \mathrm{bHLH}$ were $5^{\prime}$ primer (GCTAGCTAGCGCAGCAGCTGCCAACATAGAT) and $3^{\prime}$ primer (GCGCGAATTCTCAGCAGTATTTCCGAG). The PCR primers for creating subGRIP1 $1 \mathrm{PAS}$ were $\mathrm{N}$-terminal fragment, 5' primer (GCTAGCTAGCATGAGTGGGATGGGA) and $3^{\prime}$ primer (GCGCGGTACCCAGGTTCTTGACAAATTC). C-terminal fragment, $5^{\prime}$ primer (GCGCGGTACCCAGTCCT GCTTGATTTGT) and $3^{\prime}$ primer (GCGCGAATTCTCAGCAG TATTTCCGAG). The resultant products were inserted into NheI and EcoRI sites of the pcDNA3.1(-) plasmid (Invitrogen).

\section{Real-time reverse transcriptase ( $R T-P C R)$}

The ABI PRIZM 7700 Sequence Detector and the TaqMan EZ RT-PCR Kit (Applied Biosystem) were used for realtime RT-PCR experiments. The primers and probes used 
were c-Myc forward primer, GCCACGTCTCCACACATCAG; c-Myc reverse primer, TCTTGGCAGCAGGATAGTCCTT; and $\mathrm{c}-\mathrm{Myc}$ probe, 6FAM-ACGCAGCGCCTCCCTCCACTCTAMRA. IGF-I forward primer, TGCTTCCGGAGCTGTGATC; IGF-I reverse primer, AGCTGACTTGGCAGGCTTGA; and IGF-I probe, 6FAM-AGGAGGCTGGAGATGTATTGCGCACCTAMRA. EBAG9 forward primer, GATGCACCCACCAGTG TAAAGA; EBAG9 reverse primer, AGTCAGGTTCCAGTT GTTCCAAAG; and EBAG9 probe, 6FAM-AGGAGGGAATGG GAATGTGGCAACAC-TAMRA. PSA forward primer, TGTCT CGGATTGTGGGAGG; PSA reverse primer, CACAAGCACC TGCCAGGG; and PSA probe, 6FAM-TGGGAGTGCGAGAA GCATTCCCA-TAMRA.

\section{RNAi}

Vector-based RNAi was utilized. Vectors were constructed by inserting a synthesized 64-mer oligonucleotide containing a specific sequence for SRC-1, GRIP1, or AIB1 into pSUPER vector (Brummelkamp et al. 2002). For SRC-1, the sequence was $5^{\prime}$-CCTCAGGGCAGAGAACCATC-3'; for GRIP1, the sequence was 5'-CCTGGAAGGCAACGTTGTG-3'; and for AIB1, the sequence was 5'-GATATAATCCGAAGGTGTA-3'. Each of these sequences was synthesized in reverse orientation spaced by 6 nucleotides in the 64-mer oligonucleotide. After annealing into a double strand followed by phosphorylation, the 64-mer was ligated into the pSUPER vector. The vector was then transfected into cells with the LIPOFECTAMINE 2000 Reagent (Invitrogen Corp.). Forty-eight hours after transfection, cells were treated with E2 or DHT for different times. The TRIZOL reagent was used to extract total RNA for measuring mRNA level by real-time RT-PCR. Transfection efficiency was monitored by cotransfection with an Escherichia coli lacZ construct (pcDNA4/His/Max/lacZ; Invitrogen Corp.).

\section{Tissue samples}

Breast cancer tissues were obtained from surgical specimens from patients with breast cancer. Samples were selected from patients for whom complete information on clinical tumor size, nodal status, and ER status was available. Samples were frozen in liquid nitrogen immediately after surgical removal and maintained at $-80^{\circ} \mathrm{C}$ until use for RNA extraction. All studies were approved by the Ethics Committee of the Peking University Health Science Center.

\section{Acknowledgments}

We thank Joanne B. Green for assistance with the manuscript preparation. This work was supported by grants (30225043 and 30393110 to Y.S.) from National Natural Science Foundation of China and a grant (2002BA711A01-05 to Y.S.) from the Ministry of Science and Technology of China.

The publication costs of this article were defrayed in part by payment of page charges. This article must therefore be hereby marked "advertisement" in accordance with 18 USC section 1734 solely to indicate this fact.

\section{References}

Anzick, S.L., Kononen, J., Walker, R.L., Azorsa, D.O., Tanner, M.M., Guan, X.Y., Sauter, G., Kallioniemi, O.P., Trent, J.M., and Meltzer, P.S. 1997. AIB1, a steroid receptor coactivator amplified in breast and ovarian cancer. Science 277: 965-968.
Augereau, P., Miralles, F., Cavailles, V., Gaudelet, C., Parker, M., and Rochefort, H. 1994. Characterization of the proximal estrogen-responsive element of human cathepsin D gene. Mol. Endocrinol. 8: 693-703.

Barkhem, T., Haldosen, L.A., Gustafsson, J.A., and Nilsson, S. 2002. Transcriptional synergism on the pS2 gene promoter between a p160 coactivator and estrogen receptor- $\alpha$ depends on the coactivator subtype, the type of estrogen response element, and the promoter context. Mol. Endocrinol. 16: 2571-2581.

Bautista, S., Valles, H., Walker, R.L., Anzick, S., Zeillinger, R., Meltzer, P., and Theillet, C. 1998. In breast cancer, amplification of the steroid receptor coactivator gene AIB1 is correlated with estrogen and progesterone receptor positivity. Clin. Cancer Res. 4: 2925-2929.

Beischlag, T.V., Wang, S., Rose, D.W., Torchia, J., Reisz-Porszasz, S., Muhammad, K., Nelson, W.E., Probst, M.R., Rosenfeld, M.G., and Hankinson, O. 2002. Recruitment of the NCoA/SRC-1/p160 family of transcriptional coactivators by the aryl hydrocarbon receptor/aryl hydrocarbon receptor nuclear translocator complex. Mol. Cell. Biol. 22: 4319-4333.

Bieche, I., Laurendeau, I., Tozlu, S., Olivi, M., Vidaud, D., Lidereau, R., and Vidaud, M. 1999. Quantitation of MYC gene expression in sporadic breast tumors with a real-time reverse transcription-PCR assay. Cancer Res. 59: 2759-2765.

Bieche, I., Parfait, B., Tozlu, S., Lidereau, R., and Vidaud, M. 2001. Quantitation of androgen receptor gene expression in sporadic breast tumors by real-time RT-PCR: Evidence that

MYC is an AR-regulated gene. Carcinogenesis 22: 1521-1526.

Bommer, M., Benecke, A., Gronemeyer, H., and Rochette-Egly, C. 2002. TIF2 mediates the synergy between RAR $\alpha 1$ activation functions AF-1 and AF-2. J. Biol. Chem. 277: 3796137966.

Brummelkamp, T.R., Bernards, R., and Agami, R. 2002. A system for stable expression of short interfering RNAs in mammalian cells. Science 296: 550-553.

Carapeti, M., Aguiar, R.C., Goldman, J.M., and Cross, N.C. 1998. A novel fusion between $\mathrm{MOZ}$ and the nuclear receptor coactivator TIF2 in acute myeloid leukemia. Blood 91: 3127-3133.

Champagne, N., Pelletier, N., and Yang, X.J. 2001. The monocytic leukemia zinc finger protein MOZ is a histone acetyltransferase. Oncogene 20: 404-409.

Chen, D., Huang, S.M., and Stallcup, M.R. 2000. Synergistic, p160 coactivator-dependent enhancement of estrogen receptor function by CARM1 and p300. J. Biol. Chem. 275: 4081040816.

Chrzan, P., Skokowski, J., Karmolinski, A., and Pawelczyk, T. 2001. Amplification of c-myc gene and overexpression of c-Myc protein in breast cancer and adjacent non-neoplastic tissue. Clin. Biochem. 34: 557-562.

Cleutjens, K.B., van Eekelen, C.C., van der Korput, H.A., Brinkmann, A.O., and Trapman, J. 1996. Two androgen response regions cooperate in steroid hormone regulated activity of the prostate-specific antigen promoter. J. Biol. Chem. 271: 6379-6388.

Cleutjens, K.B., van der Korput, H.A., van Eekelen, C.C., van Rooij, H.C., Faber, P.W., and Trapman, J. 1997. An androgen response element in a far upstream enhancer region is essential for high, androgen-regulated activity of the prostate-specific antigen promoter. Mol. Endocrinol. 11: 148-161.

Darimont, B.D., Wagner, R.L., Apriletti, J.W., Stallcup, M.R., Kushner, P.J., Baxter, J.D., Fletterick, R.J., and Yamamoto, K.R. 1998. Structure and specificity of nuclear receptor-coactivator interactions. Genes \& Dev. 12: 3343-3356. 
D'Cruz, C.M., Gunther, E.J., Boxer, R.B., Hartman, J.L., Sintasath, L., Moody, S.E., Cox, J.D., Ha, S.I., Belka, G.K., Golant, A., et al. 2001. c-MYC induces mammary tumorigenesis by means of a preferred pathway involving spontaneous Kras2 mutations. Nat. Med. 7: 235-239.

Dubik, D. and Shiu, R.P. 1992. Mechanism of estrogen activation of c-myc oncogene expression. Oncogene 7: 1587-1594.

Gehin, M., Mark, M., Dennefeld, C., Dierich, A., Gronemeyer, H., and Chambon, P. 2002. The function of TIF2/GRIP1 in mouse reproduction is distinct from those of SRC-1 and p/CIP. Mol. Cell. Biol. 22: 5923-5937.

Glass, C.K. and Rosenfeld, M.G. 2000. The coregulator exchange in transcriptional functions of nuclear receptors. Genes \& Dev. 14: 121-141.

Guerin, M., Barrois, M., Terrier, M.J., Spielmann, M., and Riou, G. 1988. Overexpression of either c-myc or c-erbB-2/neu proto-oncogenes in human breast carcinomas: Correlation with poor prognosis. Oncogene Res. 3: 21-31.

Heery, D.M., Kalkhoven, E., Hoare, S., and Parker, M.G. 1997. A signature motif in transcriptional co-activators mediates binding to nuclear receptors. Nature 387: 733-736.

Issa, L.L., Leong, G.M., Barry, J.B., Sutherland, R.L., and Eisman, J.A. 2001. Glucocorticoid receptor-interacting protein-1 and receptor-associated coactivator-3 differentially interact with the vitamin D receptor (VDR) and regulate VDR-retinoid X receptor transcriptional cross-talk. Endocrinology 142: 1606-1615.

Kim, J.H., Li, H., and Stallcup, M.R. 2003. CoCoA, a nuclear receptor coactivator which acts through an $\mathrm{N}$-terminal activation domain of p160 coactivators. Mol. Cell 12: 1537-1549.

Koh, S.S., Chen, D., Lee, Y.H., and Stallcup, M.R. 2001. Synergistic enhancement of nuclear receptor function by p160 coactivators and two coactivators with protein methyltransferase activities. J. Biol. Chem. 276: 1089-1098.

Kraichely, D.M., Sun, J., Katzenellenbogen, J.A., and Katzenellenbogen, B.S. 2000. Conformational changes and coactivator recruitment by novel ligands for estrogen receptor- $\alpha$ and estrogen receptor- $\beta$ : Correlations with biological character and distinct differences among SRC coactivator family members. Endocrinology 141: 3534-3545.

Lemon, B.D. and Freedman, L.P. 1999. Nuclear receptor cofactors as chromatin remodelers. Curr. Opin. Genet. Dev. 9: 499-504.

Louie, M.C., Yang, H.Q., Ma, A.-H., Xu, W., Zou, J.X., Kung, H.-J., and Chen, H.-W. 2003. Androgen-induced recruitment of RNA polymerase II to a nuclear receptor-p160 coactivator complex. Proc. Natl. Acad. Sci. 100: 2226-2230.

McInerney, E.M., Rose, D.W., Flynn, S.E., Westin, S., Mullen, T.M., Krones, A., Inostroza, J., Torchia, J., Nolte, R.T., AssaMunt, N., et al. 1998. Determinants of coactivator LXXLL motif specificity in nuclear receptor transcriptional activation. Genes \& Dev. 12: 3357-3368.

Metivier, R., Penot, G., Hubner, M.R., Reid, G., Brand, H., Kos, M., and Gannon, F. 2003. Estrogen receptor- $\alpha$ directs ordered, cyclical, and combinatorial recruitment of cofactors on a natural target promoter. Cell 115: 751-763.

Naidu, R., Wahab, N.A., Yadav, M., and Kutty, M.K. 2002. Protein expression and molecular analysis of c-myc gene in primary breast carcinomas using immunohistochemistry and differential polymerase chain reaction. Int. J. Mol. Med. 9: 189-196.

Nasi, S., Ciarapica, R., Jucker, R., Rosati, J., and Soucek, L. 2001. Making decisions through Myc. FEBS Lett. 490: 153-162.

Picard, F., Gehin, M., Annicotte, J.S., Rocchi, S., Champy, M.F., O'Malley, B.W., Chambon, P., and Auwerx, J. 2002. SRC-1 and TIF2 control energy balance between white and brown adipose tissues. Cell 111: 931-941.

Rachez, C. and Freedman, L.P. 2001. Mediator complexes and transcription. Curr. Opin. Cell. Biol. 13: 274-280.

Shang, Y. and Brown, M. 2002. Molecular determinants for the tissue specificity of SERMs. Science 295: 2465-2468.

Shang, Y., Hu, X., DiRenzo, J., Lazar, M.A., and Brown, M. 2000. Cofactor dynamics and sufficiency in estrogen receptorregulated transcription. Cell 103: 843-852.

Shang, Y., Myers, M., and Brown, M. 2002. Formation of the androgen receptor transcription complex. Mol. Cell 9: 601-610.

Silva, I.S., Morsch, D.M., Urnauer, L., and Spritzer, P.M. 2001. Androgen-induced cell growth and c-myc expression in human non-transformed epithelial prostatic cells in primary culture. Endocr. Res. 27: 153-169.

Tsuchiya, F., Ikeda, K., Tsutsumi, O., Hiroi, H., Momoeda, M., Taketani, Y., Muramatsu, M., and Inoue, S. 2001. Molecular cloning and characterization of mouse EBAG9, homolog of a human cancer associated surface antigen: Expression and regulation by estrogen. Biochem. Biophys. Res. Commun. 284: 2-10.

Umayahara, Y., Kawamori, R., Watada, H., Imano, E., Iwama, N., Morishima, T., Yamasaki, Y., Kajimoto, Y., and Kamada, T. 1994. Estrogen regulation of the insulin-like growth factor I gene transcription involves an AP-1 enhancer. I. Biol. Chem. 269: 16433-16442.

Wang, Z., Rose, D.W., Hermanson, O., Liu, F., Herman, T., Wu, W., Szeto, D., Gleiberman, A., Krones, A., Pratt, K., et al. 2000. Regulation of somatic growth by the p160 coactivator p/CIP. Proc. Natl. Acad. Sci. 97: 13549-13554.

Watanabe, T., Inoue, S., Hiroi, H., Orimo, A., Kawashima, H., and Muramatsu, M. 1998. Isolation of estrogen-responsive genes with a CpG island library. Mol. Cell. Biol. 18: 442-449.

Weiss, R.E., Xu, J., Ning, G., Pohlenz, J., O'Malley, B.W., and Refetoff, S. 1999. Mice deficient in the steroid receptor coactivator 1 (SRC-1) are resistant to thyroid hormone. EMBO J. 18: 1900-1904.

Xu, J., Qiu, Y., DeMayo, F.J., Tsai, S.Y., Tsai, M.J., and O'Malley, B.W. 1998. Partial hormone resistance in mice with disruption of the steroid receptor coactivator-1 (SRC-1) gene. Science 279: 1922-1925.

Xu, J., Liao, L., Ning, G., Yoshida-Komiya, H., Deng, C., and O'Malley, B.W. 2000. The steroid receptor coactivator SRC-3 (p/CIP/RAC3/AIB1/ACTR/TRAM-1) is required for normal growth, puberty, female reproductive function, and mammary gland development. Proc. Nat1. Acad. Sci. 97: 6379-6384.

Yu, Q., Geng, Y., and Sicinski, P. 2001. Specific protection against breast cancers by cyclin D1 ablation. Nature 411: 1017-1021. 


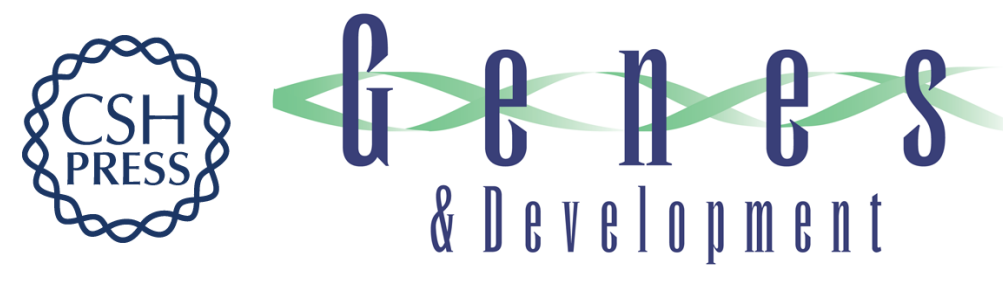

\section{Differential gene regulation by the SRC family of coactivators}

Hua Zhang, Xia Yi, Xiaojing Sun, et al.

Genes Dev. 2004, 18:

Access the most recent version at doi:10.1101/gad.1194704

Supplemental

Material

References

License

Email Alerting Service
http://genesdev.cshlp.org/content/suppl/2004/06/18/18.14.1753.DC1

This article cites 46 articles, 21 of which can be accessed free at: http://genesdev.cshlp.org/content/18/14/1753.full.html\#ref-list-1

Receive free email alerts when new articles cite this article - sign up in the box at the top right corner of the article or click here.

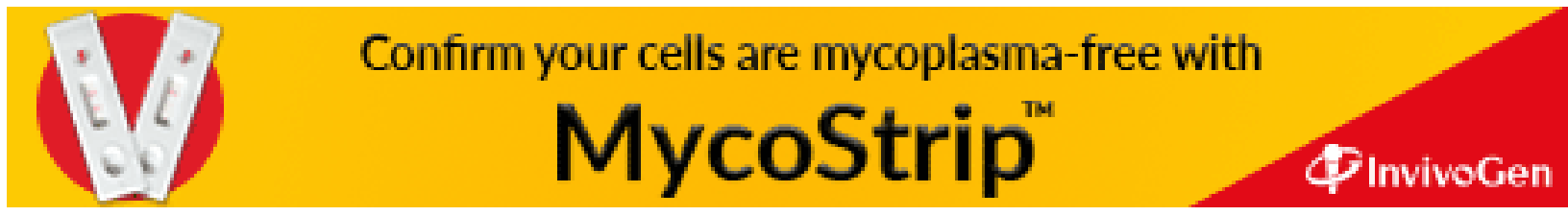

